\title{
Genetic and Pathogenic Variability of Fusarium oxysporum f. sp. cepae Isolated from Onion and Welsh Onion in Japan
}

\author{
Kazunori Sasaki, Katsuya Nakahara, Shuhei Tanaka, Masayoshi Shigyo, and Shin-ichi Ito
}

First author: The United Graduate School of Agricultural Sciences, Tottori University, 4-101 Koyama-Minami, Tottori, 680-8553, Japan; and second, third, fourth, and fifth authors: Department of Biological and Environmental Sciences, Faculty of Agriculture, Yamaguchi University, Yamaguchi, 753-8515, Japan.

Accepted for publication 9 October 2014.

\begin{abstract}
Sasaki, K., Nakahara, K., Tanaka, S., Shigyo, M., and Ito, S. 2015. Genetic and pathogenic variability of Fusarium oxysporum f. sp. cepae isolated from onion and Welsh onion in Japan. Phytopathology 105:525-532.

Fusarium oxysporum f. sp. cepae causes Fusarium basal rot in onion (common onion) and Fusarium wilt in Welsh onion. Although these diseases have been detected in various areas in Japan, knowledge about the genetic and pathogenic variability of $F$. oxysporum f. sp. cepae is very limited. In this study, F. oxysporum f. sp. cepae was isolated from onion and Welsh onion grown in 12 locations in Japan, and a total of $55 \mathrm{~F}$. oxysporum f. sp. cepae isolates (27 from onion and 28 from Welsh onion) were characterized based on their rDNA intergenic spacer (IGS) and

translation elongation factor-1 $\alpha(\mathrm{EF}-1 \alpha)$ nucleotide sequences, vegetative compatibility groups (VCGs), and the presence of the SIX (secreted in xylem) homologs. Phylogenetic analysis of IGS sequences showed that these isolates were grouped into eight clades (A to $\mathrm{H}$ ), and 20 onion isolates belonging to clade $\mathrm{H}$ were monophyletic and assigned to the same VCG. All the IGS-clade H isolates possessed homologs of SIX3, SIX5, and SIX7. The SIX3 homolog was located on a 4 Mb-sized chromosome in the IGS-clade $\mathrm{H}$ isolates. Pathogenicity tests using onion seedlings showed that all the isolates with high virulence were in the IGSclade $\mathrm{H}$. These results suggest that $F$. oxysporum f. sp. cepae isolates belonging to the IGS-clade $\mathrm{H}$ are genetically and pathogenically different from those belonging to the other IGS clades.
\end{abstract}

The common onion (Allium cepa L.) is one of the most important vegetables grown worldwide, with a production of $82 \mathrm{mt}(1.1 \mathrm{mt}$ in Japan) in 2012 (9). Welsh onion (A. fistulosum L.), also known as Japanese bunching onion, is one of the most commonly cultivated vegetables in East Asia, especially in Japan and China $(14,44)$. Young seedlings as well as adult Welsh onions are high-value farm products used as ingredients for hors d'oeuvres, soup, and sushi in Japan. Welsh onion is therefore cultivated continuously throughout the year to cater to the market demand in Japan (7). Both onion and Welsh onion are popular vegetables in Japan; their areas of cultivation are 24,900 and 23,000 ha, ranking sixth and seventh in vegetable acreage in 2012, respectively (9). Both onion and Welsh onion are attacked by many fungal pathogens, including Fusarium oxysporum in Japan $(7,19,35)$.

Fusarium basal rot of onion, caused by F. oxysporum f. sp. cepae W. C. Snyder \& H. N. Hansen, is an important soilborne disease that occurs widely in onion-growing areas and during the storage of onion bulbs (31). F. oxysporum f. sp. cepae also causes Fusarium wilt in Welsh onion $(7,18,35)$. Fusarium basal rot and wilt have become major diseases causing considerable economic damage to both onion and Welsh onion production in recent years in Japan (7). Although the reasons for the increase in the occurrence of both diseases have not been determined, long-term continuous cropping and environmental changes, including higher temperatures and heavier summer rainfall in recent years in Japan, may be influencing the increase.

Genetic and pathogenic characterization of $F$. oxysporum f. sp. cepae distributed in Japan is useful for efficient management of onion and Welsh onion production. The vegetative compatibility group (VCG) approach has been demonstrated to be a valuable

Corresponding author: S. Ito; E-mail address: shinsan@yamaguchi-u.ac.jp method for characterizing the genetic variability of $F$. oxysporum f. sp. cepae $(3,33,34,43)$. Widodo et al. (43) reported that $F$. oxysporum f. sp. cepae isolated from onion in Hokkaido, the northernmost island of Japan, were grouped into four VCGs and two single self-compatible isolates. Vegetative compatibility is mediated by the multiple vegetative incompatibility (vic) loci (21). The isolates classified in the same VCG were closely related genetically because they form stable heterokaryons only if each vic loci of the isolate is identical. Another method used in the genetic characterization within a forma specialis (f. sp.) of $F$. oxysporum involves analyzing the nucleotide sequences of the ribosomal DNA intergenic spacer (IGS) region (25); this method has also been applied in investigating genetic variability in $F$. oxysporum f. sp. cepae $(3,6,33)$. Dissanayake et al. (6) isolated $F$. oxysporum f. sp. cepae from wilted Welsh onion in Japan and reported that these isolates share polyphyletic origins as well as a relationship with the phylogenic position of the isolates based on IGS sequences and their pathogenicity to Welsh onion cultivars. However, no information is available about the genetic and pathogenic variability of $F$. oxysporum f. sp. cepae isolates from onion in Japan. In addition, there have been very few studies on the genetic and pathogenic variability among the $F$. oxysporum $\mathrm{f}$. sp. cepae isolates from onion and Welsh onion.

Unlike $F$. oxysporum f. sp. cepae, the genetic and pathogenic variability in $F$. oxysporum $\mathrm{f}$. sp. lycopersici, the causative agent of Fusarium wilt in tomato, have been studied in great detail. Recent studies revealed that $F$. oxysporum $\mathrm{f}$. sp. lycopersici strains secrete effector proteins into xylem, referred to as the secreted in xylem (SIX) proteins. So far, 14 SIX genes (SIX1 to SIX14) have been identified in F. oxysporum f. sp. lycopersici $(12,23,24,27,28,39,40)$. Although SIX genes were initially believed to be unique to F. oxysporum f. sp. lycopersici, some of them have been detected in other forma specialis as well $(4,11,16,23,37)$. Thus far, however, the SIX3 and SIX5 genes have been detected only in the genome of F. oxysporum f. sp. lycopersici. These results led us to hypothesize 
that $F$. oxysporum f. sp. cepae may have SIX gene homologs, which may be associated with its pathogenicity.

In this study, the genetic and pathogenic variability in the $F$. oxysporum $\mathrm{f}$. sp. cepae isolates from onion and Welsh onion grown in Japan were analyzed with respect to their VCG and IGS sequences. The $F$. oxysporum f. sp. cepae isolates were also examined for the presence of $S I X$ genes in their genomes.

\section{MATERIALS AND METHODS}

Fungal isolates. Onion and Welsh onion plants with typical symptoms of Fusarium basal rot and Fusarium wilt, respectively, were collected from 12 locations (Hokkaido, Fukushima, Saitama, Shizuoka, Aichi, Mie, Kyoto, Hyogo, Tokushima, Kochi, Saga, and Kagoshima) in Japan. Basal plates of diseased plants were surfacesterilized in $80 \%$ ethanol for $30 \mathrm{~s}$, which was followed by suspending them in $0.5 \% \mathrm{NaOCl}$ for $30 \mathrm{~s}$, and then rinsing in sterile distilled water. Basal plates ( 3 to $5 \mathrm{~mm}$ in diameter) were placed onto Fusarium selective medium (20) and incubated for 1 week at $25^{\circ} \mathrm{C}$ in the dark. The pure cultures of the isolates were obtained using a single-spore culture technique (22).

DNA extraction and identification of Fusarium spp. based on their ITS sequences. For DNA extraction, the fungal isolates were cultured in potato dextrose broth (PDB) for 3 days at $25^{\circ} \mathrm{C}$ in the dark, and the fungal mycelia were harvested by filtering the broth through sterile filter paper (Advantec, Tokyo, Japan). DNA was extracted from the mycelia using a Dr. GenTLE (from Yeast) (Takara Bio, Shiga, Japan), according to the manufacturer's instructions.

The fungal species were identified on the basis of morphology (22) and their ribosomal DNA internal transcribed spacer (ITS) region sequences. Polymerase chain reaction (PCR) amplification of the ITS regions was performed using the primers ITS1 and ITS4 (42). The PCR consisted of $20 \mathrm{ng}$ of genomic DNA, $2 \mu \mathrm{l}$ of $10 \times$ buffer (Takara Bio), $1.6 \mu \mathrm{l}$ of $2.5 \mathrm{mM}$ each dNTP, $0.2 \mu \mathrm{M}$ of each primer, and $0.2 \mathrm{U}$ of Ex-Taq polymerase (Takara Bio) in a total reaction mixture of $20 \mu \mathrm{l}$. An initial denaturation step of $94^{\circ} \mathrm{C}$ for 2 min was followed by 35 cycles of denaturation at $94^{\circ} \mathrm{C}$ for $30 \mathrm{~s}$, annealing at $55^{\circ} \mathrm{C}$ for $30 \mathrm{~s}$, and extension at $72^{\circ} \mathrm{C}$ for $40 \mathrm{~s}$, with a final extension step at $72^{\circ} \mathrm{C}$ for $5 \mathrm{~min}$. PCR products were purified by ethanol precipitation and labeled using the BigDye Terminator v3.1 Cycle Sequencing Kit (Applied Biosystems, Foster City, CA). The DNA fragments were sequenced using an ABI PRISM 3100 genetic analyzer (Applied Biosystems).

Phylogenetic analysis. The partial rDNA-IGS region was amplified using primers PNFo and PN22 (8). The translation elongation factor- $1 \alpha(\mathrm{EF}-1 \alpha)$ sequence was amplified using primers EF1 and EF2 (26). PCR conditions were the same as described for the ITS region, except that the extension time for the IGS region was $1.5 \mathrm{~min}$. Sequencing was performed using primers PNFo, PN22, and IGS2 (10) for IGS, and EF1 and EF2 for EF-1 $\alpha$. The reaction conditions were identical to those described for the ITS region. Nucleotide sequences of the partial rDNA-IGS and EF-1 $\alpha$ were aligned using ClustalW (38). Phylogenetic trees were constructed by the neighbor-joining method (29) based on Kimura's two-parameter model (17) using MEGA v.4.0 (36). The statistical reliability of each node was assessed using 1,000 bootstrap iterations. F. verticillioides (accession no. AY249379) was used as an outgroup in the IGS-based phylogenetic analysis. Fusarium spp. isolates NRRL28387 (accession no. AF246832) and NRRL25184 (accession no. AF008514) were used as outgroups in the EF-1 $\alpha$-based phylogenetic analysis.

Vegetative compatibility test and inter-retrotransposon sequence-characterized amplified regions markers. Vegetative compatibility tests were performed according to the method of Correll (5). Nitrate nonutilizing mutants were generated on minimal medium containing $4 \% \mathrm{KClO}_{3}$, and were classified as nit1, nit3, and NitM based on the differences in their utilization patterns of the nitrogen source in the medium. Heterokaryon formation was tested by pairing nit1 and NitM mutants of the isolates.

Multiplex PCR was performed using inter-retrotransposon sequence-characterized amplified regions (IR-SCAR) markers, i.e., the primer sets of HTH-1F/2R (244 bp) and Hansec-1F/2R (392 bp) (32) in a $20-\mu l$ reaction system containing $10 \mu$ l of Quick Taq HS DyeMix (Toyobo, Shiga, Japan), $0.2 \mu \mathrm{M}$ of both the primer pairs, and $20 \mathrm{ng}$ of genomic DNA. An initial denaturation step for $2 \mathrm{~min}$ at $94^{\circ} \mathrm{C}$ was followed by 35 cycles of denaturation for $30 \mathrm{~s}$ at $94^{\circ} \mathrm{C}$, annealing for $30 \mathrm{~s}$ at $60^{\circ} \mathrm{C}$, and extension for $30 \mathrm{~s}$ at $68^{\circ} \mathrm{C}$. Amplified

TABLE 1. Primers used in this study ${ }^{\mathrm{a}}$

\begin{tabular}{|c|c|c|c|}
\hline Primer name & Sequence $\left(5^{\prime}-3^{\prime}\right)$ & Target & Reference \\
\hline ITS1 & TCCGTAGGTGAACCTGCGG & ITS & $(42)$ \\
\hline ITS4 & TCCTCCGCTTATTGATATGC & ITS & $(42)$ \\
\hline PNFo & CCCGCCTGGCTGCGTCCGACTC & IGS & $(8)$ \\
\hline PN22 & CAAGCATATGACTACTGGC & IGS & (8) \\
\hline IGS2 & GCCGGATTTGCTCCCTTCT & IGS & (10) \\
\hline EF1 & ATGGGTAAGGARGACAAGAC & $\mathrm{EF}-1 \alpha$ & (26) \\
\hline $\mathrm{EF} 2$ & GGARGTACCAGTSATCATGTT & $\mathrm{EF}-1 \alpha$ & $(26)$ \\
\hline Hansec-1F & TTATTGCCCTCATCGGAAAG & IR-SCAR (392 bp) & $(32)$ \\
\hline Hansec-2R & ACCAGCATGCAGCAACAGTC & IR-SCAR (392 bp) & (32) \\
\hline HTH-1F & CATCGGAAGTGACATGGTTG & IR-SCAR (244 bp) & $(32)$ \\
\hline HTH-2R & AGGCTTTTCCAGCATTTGAA & IR-SCAR (244 bp) & (32) \\
\hline P12-F1 & CCCCGAATTGAGGTGAAG & SIX1 & $(28)$ \\
\hline P12-R1 & AATAGAGCCTGCAAAGCATG & SIX1 & $(28)$ \\
\hline SIX2-F2 & CAACGCCGTTTGAATAAGCA & SIX2 & (39) \\
\hline SIX2-R2 & TCTATCCGCTTTCTTCTCTC & SIX2 & (39) \\
\hline SIX3-F1 & CCAGCCAGAAGGCCAGTTT & SIX3 & (39) \\
\hline SIX3-R2 & GGCAATTAACCACTCTGCC & SIX3 & (39) \\
\hline SIX4-F1 & TCAGGCTTCACTTAGCATAC & SIX4 & (23) \\
\hline SIX4-R1 & GCCGACCGAAAAACCCTAA & SIX4 & $(23)$ \\
\hline SIX5-F1 & ACACGCTCTACTACTCTTCA & SIX5 & (23) \\
\hline SIX5-R1 & GAAAACCTCAACGCGGCAAA & SIX5 & (23) \\
\hline SIX6-F1 & СТCTCCTGAACCATCAACTT & SIX6 & (23) \\
\hline SIX6-R1 & CAAGACCAGGTGTAGGCATT & SIX6 & (23) \\
\hline SIX7-F1 & CATCTTTTCGCCGACTTGGT & SIX7 & (23) \\
\hline SIX7-R1 & CTTAGCACCCTTGAGTAACT & SIX7 & (23) \\
\hline
\end{tabular}

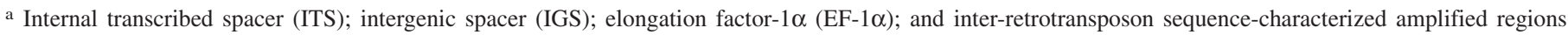
(IR-SCAR). 
products were separated by electrophoresis on a $2 \%$ agarose gel, stained with ethidium bromide, and then visualized under UV light.

Amplification of $\boldsymbol{S I X}$ homologs. Fungal DNAs were examined for the presence of the seven SIX genes (SIX1 to SIX7) by performing PCR using the specific primer pairs listed in Table 1. PCR amplification was carried out in a reaction mixture of $20 \mu \mathrm{l}$ containing $10 \mu \mathrm{l}$ of Quick Taq HS DyeMix (Toyobo, Shiga, Japan), $0.2 \mu \mathrm{M}$ of each primer, and $20 \mathrm{ng}$ of genomic DNA. Thermal cycling conditions consisted of $2 \mathrm{~min}$ at $94^{\circ} \mathrm{C}$, followed by 35 cycles of $30 \mathrm{~s}$ at $94^{\circ} \mathrm{C}, 30 \mathrm{~s}$ at $50^{\circ} \mathrm{C}$, and $45 \mathrm{~s}$ at $68^{\circ} \mathrm{C}$. Amplified products were separated by electrophoresis on a $2 \%$ agarose gel, stained with ethidium bromide, and then visualized under UV light. The genomic DNA of F. oxysporum f. sp. lycopersici (race 1) was used as the positive control.

Chromosomal Southern blot analysis. Fungal protoplasts were prepared using the methods of Akamatsu et al. (1), with slight modifications: the enzyme solution contained lysing enzymes at $10 \mathrm{mg} / \mathrm{ml}$ (Sigma-Aldrich, Tokyo, Japan) and Yatalase at $4 \mathrm{mg} / \mathrm{ml}$ (Takara Bio). Chromosomes were separated by performing contour-clamped homogeneous electric field (CHEF) gel electrophoresis in a $1.0 \%$ Certified Megabase Agarose gel (Bio-Rad, Hercules, CA) by using the CHEF-DR II system (Bio-Rad). Electrophoresis was performed in $0.5 \times \mathrm{TBE}$ buffer for $260 \mathrm{~h}$ at $4^{\circ} \mathrm{C}$, using switch times between 1,200 and $4,800 \mathrm{~s}$ at $1.5 \mathrm{~V} / \mathrm{cm}$.

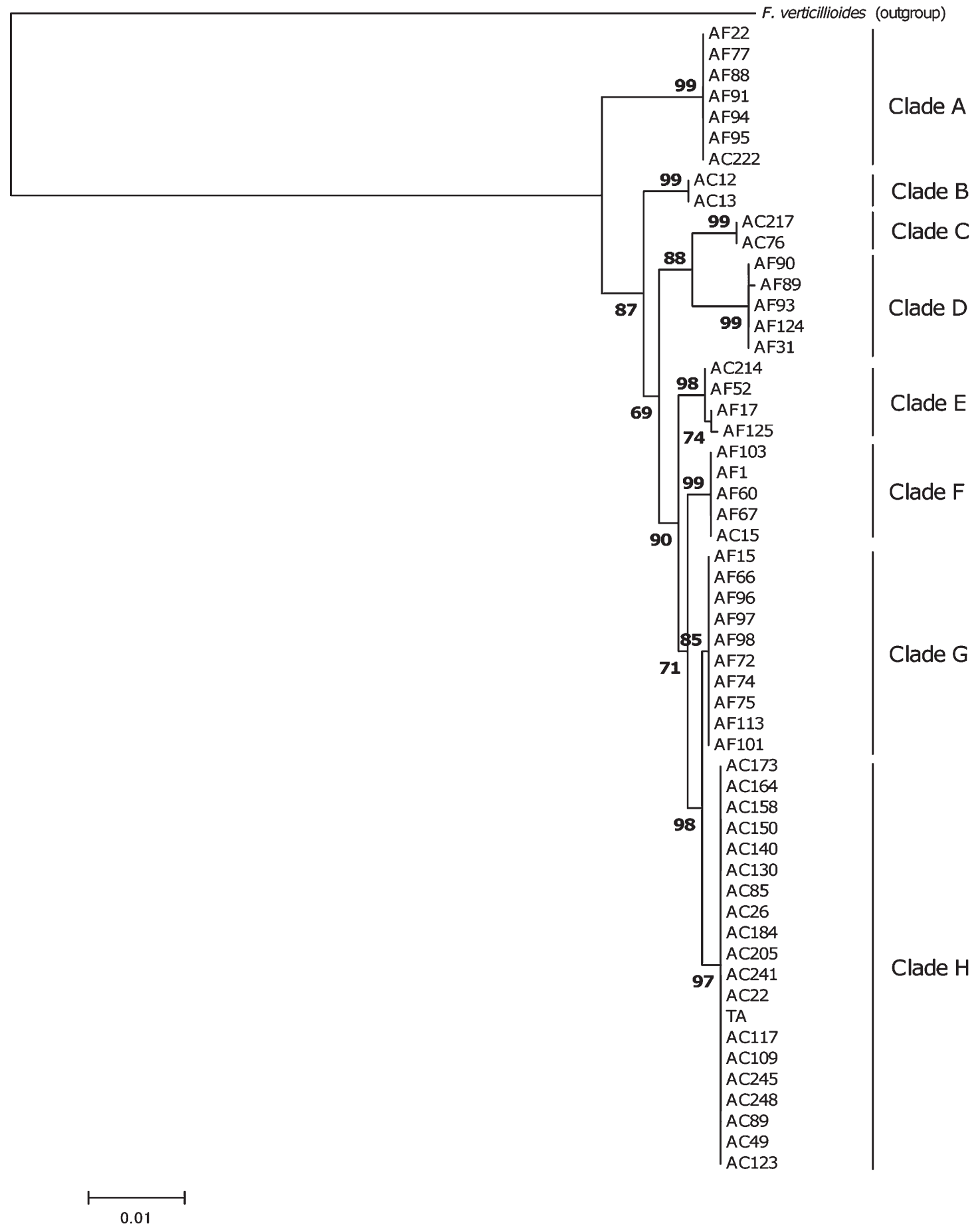

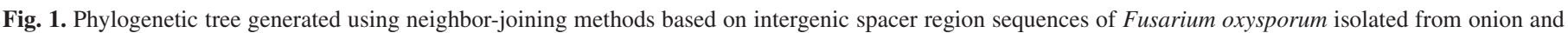

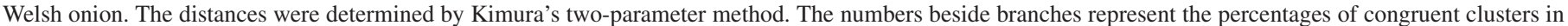
1,000 bootstrap trials, with values greater than $60 \%$. Scale bar indicates $1 \%$ sequence dissimilarity. 
Chromosomes of Saccharomyces cerevisiae (Bio-Rad) and Schizosaccharomyces pombe (Bio-Rad) were used as molecular size markers. F. oxysporum f. sp. lycopersici (race 2) was used as the positive control. Chromosome-sized DNA separated by electrophoresis was transferred to a Hybond-N+ membrane (GE Healthcare, Buckinghamshire, England) using 20× SSC for $24 \mathrm{~h}$. Chromosome localization of the SIX3 gene, Hansec, and HTH fragments was determined by performing membrane hybridization using digoxigenin (DIG)-labeled SIX3, Hansec, and HTH probes that were prepared using a DIG DNA Labeling and Detection Kit (Roche Diagnostics, Mannheim, Germany), according to the manufacturer's instructions.

Pathogenicity test using root-dip method. Fungal isolates were cultured in $\mathrm{PDB}$ for 3 days at $25^{\circ} \mathrm{C}$, and the cultures were filtered through three layers of sterile gauze cloth to remove the mycelia. The spore concentrations were estimated using a hemocytometer and adjusted to $1 \times 10^{6} \mathrm{conidia} / \mathrm{ml}$. Onion cultivars Higuma (Takii Seed, Kyoto, Japan) and Kitamomiji 2000 (Shippo Seed, Kagawa, Japan) were used as the host plants for fungi since both cultivars are extensively cultivated in Japan. Ten-day-old onion seedlings were inoculated by immersing the roots for $1 \mathrm{~h}$ at $25^{\circ} \mathrm{C}$ in a spore suspension of the isolates; control plant roots were immersed in sterile water. Seedlings were then replanted in plastic pots containing an autoclaved 4:1 mixture of sand and Takii seedling soil (Takii Seed) and maintained in a growth chamber at $25^{\circ} \mathrm{C}$, with a photoperiod of $16 \mathrm{~h}$ light $/ 8 \mathrm{~h}$ dark. The percentages of the wilted plants were determined at 3 weeks postinoculation. Each fungal isolate was inoculated in 10 seedlings and in duplicate. The experiments were replicated twice. The isolates were divided into three virulence classes based on the mean percentage of wilted plants in the two onion cultivars: high virulence $(>70 \%)$, moderate virulence (30 to $70 \%)$, and low virulence $(<30 \%)$.

\section{RESULTS}

Identification of fungal isolates from onion and Welsh onion. A total of 382 Fusarium isolates were obtained: 248 isolates

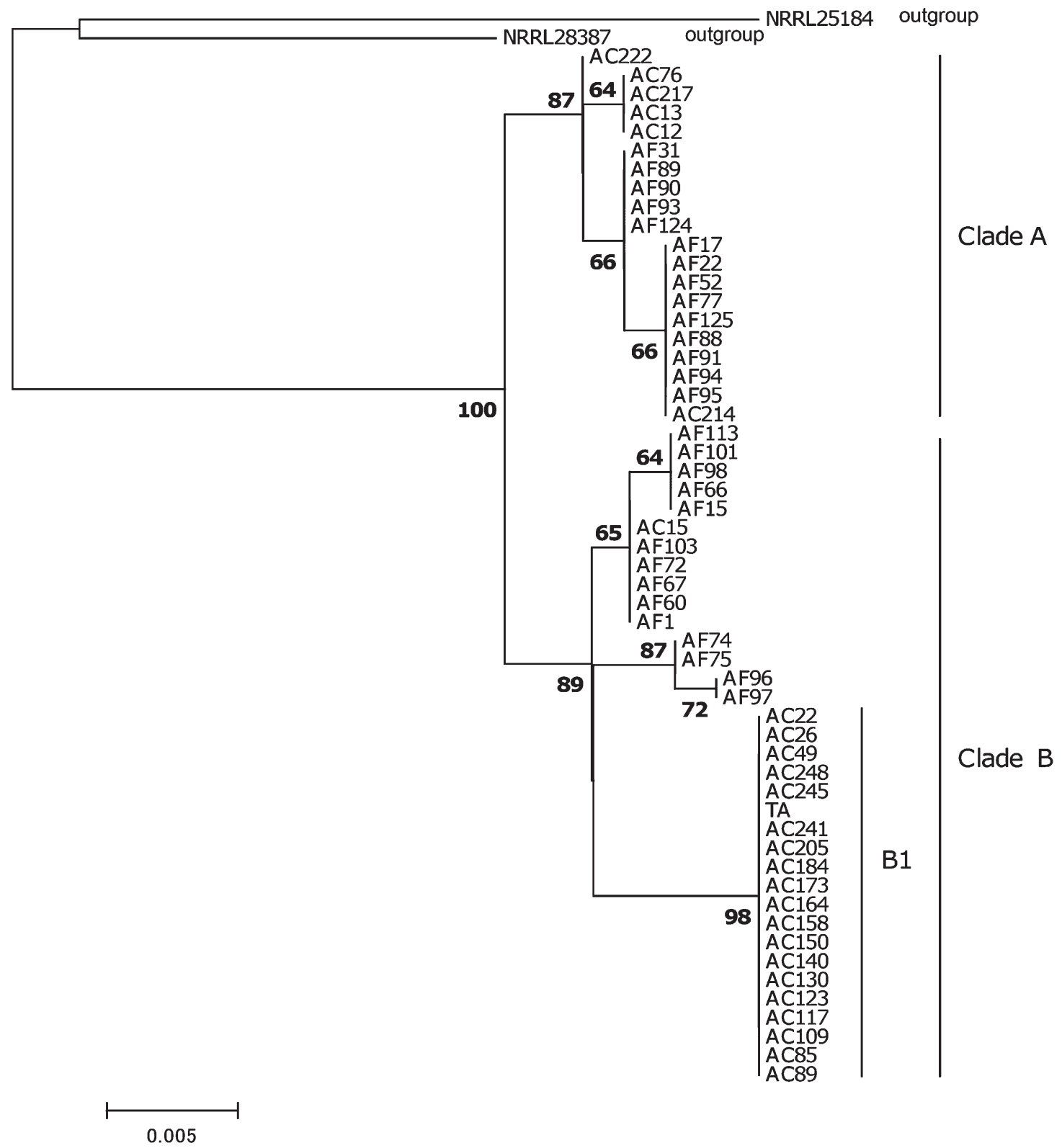

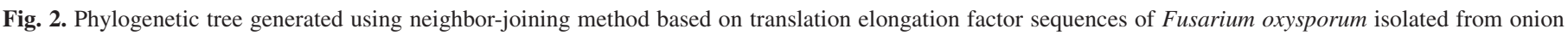

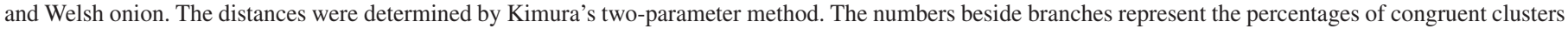
in 1,000 bootstrap trials, with values greater than $60 \%$. Scale bar indicates $0.5 \%$ sequence dissimilarity. 
from onion and 134 isolates from Welsh onion. The fungal species were identified on the basis of morphology and their ribosomal DNA ITS region sequences. The majority of isolates from onion (165 isolates) and Welsh onion (86 isolates) were identified as $F$. oxysporum. The second major Fusarium sp. isolated from both types of plant was F. solani: 69 isolates from onion and 31 from
Welsh onion. F. proliferatum was also isolated: one isolate from onion and nine isolates from Welsh onion.

Phylogenetic analysis. A total of $55 \mathrm{~F}$. oxysporum isolates, including 27 isolates from onion and 28 from Welsh onion, which together represented a broad geographical range and had been stored at $4^{\circ} \mathrm{C}$ until use, were analyzed phylogenetically based on

TABLE 2. Characteristics (pathogenicity, vegetative compatibility groups [VCGs], and SIX genes) of Fusarium oxysporum isolated from onion and Welsh onion in Japan

\begin{tabular}{|c|c|c|c|c|c|c|c|c|c|c|}
\hline \multirow[b]{2}{*}{ Isolate } & \multirow[b]{2}{*}{ Host } & \multirow[b]{2}{*}{ Regional origin } & \multirow[b]{2}{*}{ Year } & \multicolumn{2}{|c|}{$\begin{array}{l}\text { Percentage of wilted } \\
\text { plants }^{\mathrm{a}}\end{array}$} & \multirow[b]{2}{*}{$\mathrm{VCG}^{\mathrm{b}}$} & \multirow[b]{2}{*}{ IR-SCAR marker ${ }^{c}$} & \multirow[b]{2}{*}{ SIX genes ${ }^{\mathrm{d}}$} & \multicolumn{2}{|c|}{ Accession number ${ }^{\mathrm{e}}$} \\
\hline & & & & Higuma & Kitamomiji & & & & IGS & $\mathrm{EF}-1 \alpha$ \\
\hline $\mathrm{AC} 12$ & Onion & Aichi & 2010 & 5 & 15 & HIS & - & - & AB936592 & AB938050 \\
\hline $\mathrm{AC} 13$ & Onion & Aichi & 2010 & 0 & 0 & SMV16 & - & - & AB936593 & AB938051 \\
\hline $\mathrm{AC} 15$ & Onion & Aichi & 2010 & 5 & 5 & SMV17 & - & - & AB936594 & AB938052 \\
\hline $\mathrm{AC} 22$ & Onion & Hokkaido & 2011 & 45 & 20 & G4 & + & + & AB936595 & AB938053 \\
\hline AC26 & Onion & Hokkaido & 2011 & 45 & 45 & G4 & + & + & AB936596 & AB938054 \\
\hline AC49 & Onion & Hokkaido & 2011 & 35 & 70 & $\mathrm{G} 4$ & + & + & AB936597 & AB938055 \\
\hline AC76 & Onion & Hokkaido & 2011 & 15 & 0 & G5 & - & - & AB936598 & AB938056 \\
\hline $\mathrm{AC} 85$ & Onion & Hokkaido & 2011 & 60 & 70 & G4 & + & + & AB936599 & AB938057 \\
\hline AC89 & Onion & Hokkaido & 2011 & 65 & 80 & $\mathrm{G} 4$ & + & + & AB936600 & AB938058 \\
\hline AC109 & Onion & Hokkaido & 2011 & 25 & 70 & G4 & + & + & AB936601 & AB938059 \\
\hline $\mathrm{AC} 117$ & Onion & Hokkaido & 2011 & 55 & 65 & $\mathrm{G} 4$ & + & + & AB936602 & AB938060 \\
\hline $\mathrm{AC} 123$ & Onion & Hokkaido & 2011 & 55 & 85 & G4 & + & + & AB936603 & AB938061 \\
\hline $\mathrm{AC} 130$ & Onion & Hokkaido & 2011 & 80 & 85 & $\mathrm{G} 4$ & + & + & AB936604 & AB938062 \\
\hline AC140 & Onion & Hokkaido & 2011 & 85 & 65 & $\mathrm{G} 4$ & $+*$ & + & AB936605 & AB938063 \\
\hline $\mathrm{AC} 150$ & Onion & Hokkaido & 2011 & 100 & 95 & $\mathrm{G} 4$ & $+^{*}$ & + & AB936606 & AB938064 \\
\hline AC 158 & Onion & Hokkaido & 2011 & 50 & 65 & G4 & + & + & AB936607 & AB938065 \\
\hline AC164 & Onion & Hokkaido & 2011 & 55 & 55 & G4 & + & + & AB936608 & AB938066 \\
\hline $\mathrm{AC} 173$ & Onion & Hokkaido & 2011 & 35 & 35 & $\mathrm{G} 4$ & + & + & AB936609 & AB938067 \\
\hline AC184 & Onion & Hokkaido & 2011 & 40 & 30 & $\mathrm{G} 4$ & + & + & AB936610 & AB938068 \\
\hline AC205 & Onion & Hokkaido & 2011 & 100 & 90 & $\mathrm{G} 4$ & $+*$ & + & AB936611 & AB938069 \\
\hline $\mathrm{AC} 214$ & Onion & Hokkaido & 2011 & 20 & 2 & n.g. & - & - & AB936612 & AB 938070 \\
\hline AC217 & Onion & Hokkaido & 2011 & 25 & 30 & G5 & - & - & AB936613 & AB938071 \\
\hline AC222 & Onion & Hokkaido & 2011 & 10 & 25 & SMV18 & - & - & AB936614 & AB938072 \\
\hline AC241 & Onion & Hokkaido & 2011 & 45 & 55 & G4 & + & + & AB936615 & AB938073 \\
\hline AC245 & Onion & Saga & 2012 & n.t. & n.t. & G4 & + & + & AB936616 & AB938074 \\
\hline AC248 & Onion & Saga & 2012 & n.t. & n.t. & G4 & + & + & AB936617 & AB938075 \\
\hline $\mathrm{TA}$ & Onion & Hokkaido & - & 95 & 100 & $\mathrm{G} 4$ & $+*$ & + & AB936618 & AB938076 \\
\hline AF1 & Welsh onion & Saitama & 2006 & 45 & 15 & n.g. & - & - & AB936564 & AB938022 \\
\hline AF15 & Welsh onion & Kyoto & 2006 & 10 & 15 & SMV1 & - & - & AB936565 & AB938023 \\
\hline AF17 & Welsh onion & Kagoshima & 2006 & 25 & 30 & SMV2 & - & - & AB936566 & AB938024 \\
\hline $\mathrm{AF} 22$ & Welsh onion & Kagoshima & 2006 & 55 & 55 & SMV3 & - & - & AB936567 & AB938025 \\
\hline AF31 & Welsh onion & Hyogo & 2006 & 20 & 20 & G1 & - & - & AB936568 & AB938026 \\
\hline AF52 & Welsh onion & Tokushima & 2007 & 20 & 35 & SMV4 & - & - & AB936569 & AB938027 \\
\hline AF60 & Welsh onion & Kochi & 2007 & 35 & 25 & SMV5 & - & - & AB936570 & AB938028 \\
\hline AF66 & Welsh onion & Kyoto & 2008 & 5 & 5 & SMV6 & - & - & AB936571 & AB938029 \\
\hline AF67 & Welsh onion & Kyoto & 2008 & 0 & 25 & SMV7 & - & - & AB936572 & AB938030 \\
\hline AF72 & Welsh onion & Kyoto & 2008 & 10 & 10 & SMV8 & - & - & AB936573 & AB938031 \\
\hline AF74 & Welsh onion & Fukushima & 2009 & 0 & 0 & G2 & - & - & AB936574 & AB938032 \\
\hline AF75 & Welsh onion & Fukushima & 2009 & 5 & 5 & $\mathrm{G} 2$ & - & - & AB936575 & AB938033 \\
\hline AF77 & Welsh onion & Fukushima & 2009 & 30 & 35 & HIS & - & - & AB936576 & AB938034 \\
\hline AF88 & Welsh onion & Shizuoka & 2010 & 90 & 35 & SMV9 & - & - & AB936577 & AB938035 \\
\hline AF89 & Welsh onion & Shizuoka & 2010 & 15 & 45 & G1 & - & - & AB936578 & AB938036 \\
\hline AF90 & Welsh onion & Shizuoka & 2010 & 40 & 60 & SMV10 & - & - & AB936579 & AB938037 \\
\hline AF91 & Welsh onion & Shizuoka & 2010 & 35 & 95 & HIS & - & - & AB936580 & AB938038 \\
\hline AF93 & Welsh onion & Shizuoka & 2010 & 25 & 15 & G1 & - & - & AB936581 & AB938039 \\
\hline AF94 & Welsh onion & Shizuoka & 2010 & 40 & 90 & SMV11 & - & - & AB936582 & AB938040 \\
\hline AF95 & Welsh onion & Shizuoka & 2010 & 40 & 35 & SMV12 & - & - & AB936583 & AB938041 \\
\hline AF96 & Welsh onion & Tokushima & 2010 & 15 & 25 & SMV13 & - & - & AB936584 & AB938042 \\
\hline AF97 & Welsh onion & Tokushima & 2010 & 25 & 0 & SMV14 & - & - & AB936585 & AB 938043 \\
\hline AF98 & Welsh onion & Tokushima & 2010 & 5 & 0 & G3 & - & - & AB936586 & AB938044 \\
\hline AF101 & Welsh onion & Tokushima & 2010 & 15 & 30 & G3 & - & - & AB936587 & AB938045 \\
\hline AF103 & Welsh onion & Mie & 2010 & 5 & 25 & n.g. & - & - & AB936588 & AB938046 \\
\hline AF113 & Welsh onion & Saitama & 2010 & 0 & 15 & SMV15 & - & - & AB936589 & AB938047 \\
\hline AF124 & Welsh onion & Hokkaido & 2011 & n.t. & n.t. & n.g. & - & - & AB936590 & AB938048 \\
\hline AF125 & Welsh onion & Hokkaido & 2011 & n.t. & n.t. & n.g. & - & - & AB936591 & AB938049 \\
\hline
\end{tabular}

a For determining the percentage of wilted plants, two onion cultivars ('Higuma' and 'Kitamomiji 2000') were inoculated with F. oxysporum by the root-dip method. Ten seedlings were used in each experiment in duplicate. n.t. indicates not tested.

${ }^{\mathrm{b}}$ HSI; heterokaryon self-incompatible. n.g; generated either nit1 or NitM mutant. SMV; single member of VCG.

${ }^{c}+$ indicates that two polymerase chain reaction (PCR) products (392 and 244 bp) were obtained using inter-retrotransposon sequence-characterized amplified regions (IR-SCAR) marker primers. +* indicates that only 392-bp product was obtained. - indicates that no PCR products were obtained.

d + indicates that PCR products were obtained with specific primers of SIX3, SIX5, and SIX7. - indicates that no PCR products were obtained.

e GenBank/DDBJ accession number of partial rDNA intergenic spacer (IGS) and elongation factor-1 $\alpha$ (EF-1 $\alpha$ ) sequences determined in this study. 
their IGS and EF-1 $\alpha$ nucleotide sequences. A phylogenetic tree based on the IGS sequences revealed that the 55 isolates were divided into eight clades, A to H (Fig. 1). No clade was related to its geographic origin. Most of the isolates from onions grown in Hokkaido and Saga were in clade H; the IGS sequences of the isolates of clade $\mathrm{H}$ shared $100 \%$ nucleotide identity. A phylogenetic tree based on EF-1 $\alpha$ branched into two clades (Fig. 2). All the isolates belonging to clade $\mathrm{H}$ of the IGS-based phylogenetic tree were grouped into a subclade (B1), with $100 \%$ nucleotide identity with the EF-1 $\alpha$-based phylogenetic tree; while the other isolates belonging to clades other than $\mathrm{H}$ in the IGS-based phylogenic tree had no relationship with the clades in the EF- $1 \alpha$-based phylogenetic tree. In both phylogenetic trees, a high degree of genetic variability was observed among the Welsh onion isolates.

Vegetative compatibility and IR-SCAR markers. Hypochlorite-resistant mutants of each isolate were designated as nit1, nit3, or NitM based on the differences in their utilization patterns of the nitrogen source in the medium. Out of 55 isolates, five (AF1, AF103, AF124, AF125, and AC214) could not be used in the pairing test because they generated neither nit1 nor NitM mutants. Three isolates (AF77, AF91, and AC12) showed heterokaryon self-incompatible (HSI) phenotypes. Five VCGs and 18 single members of VCG (SMV) were obtained from the 47 isolates tested (Table 2). All the isolates belonging to clade $\mathrm{H}$ of the IGS-based phylogenic tree formed heterokaryons with each of the isolates in the VCG group 4 (G4).

IR-SCAR markers have been reported to identify VCG0421 and VCG0425 of $F$. oxysporum f. sp. cepae (32); the IR-SCAR marker generated two bands (392 bp with Hansec primers and 244 bp with HTH primers) from $F$. oxysporum f. sp. cepae VCG0421 and VCG0425. In our experiments, PCR amplification using IR-SCAR marker primers produced bands ( 392 and $244 \mathrm{bp}$ ) that were detected only in the isolates of clade $\mathrm{H}$ of the IGS-based phylogenetic tree. Among those, AC140, AC150, AC205, and TA generated only a 392-bp band. No amplified products were detected in the isolates other than the H-clade isolates (Table 2).

Presence of SIX homologs. All the isolates used in the phylogenetic analysis (55 isolates) were also examined for the presence of the seven SIX genes by performing PCR. The SIX3, SIX 5, and SIX7 amplicons were generated from the DNA of all the isolates of the IGS-clade H. In contrast, no SIX amplicons were detected in the isolates other than the H-clade isolates (Table 2).
Chromosomal location of SIX3 homolog and IR-SCAR marker amplicons. Fungal chromosomes were separated in CHEF gels, and the chromosomal locations of the SIX homologs were determined by performing Southern blot analysis, which revealed that the SIX3 homolog was located on a $4 \mathrm{Mb}$-sized chromosome in the F. oxysporum f. sp. cepae isolates of IGS-clade $\mathrm{H}$ (Fig. 3A). CHEF blots probed using the Hansec fragment (392 bp) also indicated the presence of the $4 \mathrm{Mb}$ chromosome of the IGSclade $\mathrm{H}$ isolates (AC109 and TA). However, although the HTH fragment (244 bp) hybridized to the $4 \mathrm{Mb}$ chromosome of isolate AC109, it did not hybridize to any chromosome of TA; a result consistent with those of IR-SCAR PCR (Fig. 3B). These data show that the SIX3 homologs as well as the target regions of the IR-SCAR markers were located on the same chromosome of the H-clade isolates.

Inoculation test. Fungal isolates were examined for their virulence in onion seedlings of two cultivars. Most of the onion isolates belonging to clade $\mathrm{H}$ of the IGS-based phylogenetic tree showed moderate or high virulence in the onion seedlings of the two onion cultivars. Among those, AC150, AC205, and TA had higher virulence, causing wilt symptoms in more than $90 \%$ of the plants tested. Onion isolates belonging to the other clades of the IGS-based phylogenetic tree showed low or no virulence in the onion seedlings (Table 2).

Most of the fungal isolates from Welsh onion showed low or moderate virulence in onion seedlings, excluding AF88, which was highly virulent in 'Higuma', and AF91 and AF95, both of which were highly virulent in 'Kitamomiji 2000' (Table 2).

\section{DISCUSSION}

To the best of our knowledge, here we revealed for the first time the phylogenetic relationships among $F$. oxysporum isolated from onion and Welsh onion in Japan. Welsh onion isolates were polyphyletic in the phylogenetic tree based on the IGS sequences, supporting previous results reported by Dissanayake et al. (6). We also found that there was no relationship between the geographical origin and each clade of the phylogenetic tree based on IGS sequences of the isolates. In contrast, most of the onion isolates were monophyletic and were confined to IGS-clade H. Seven onion isolates not belonging to IGS-clade $\mathrm{H}$ (AC12, AC13, AC15, AC76,
A

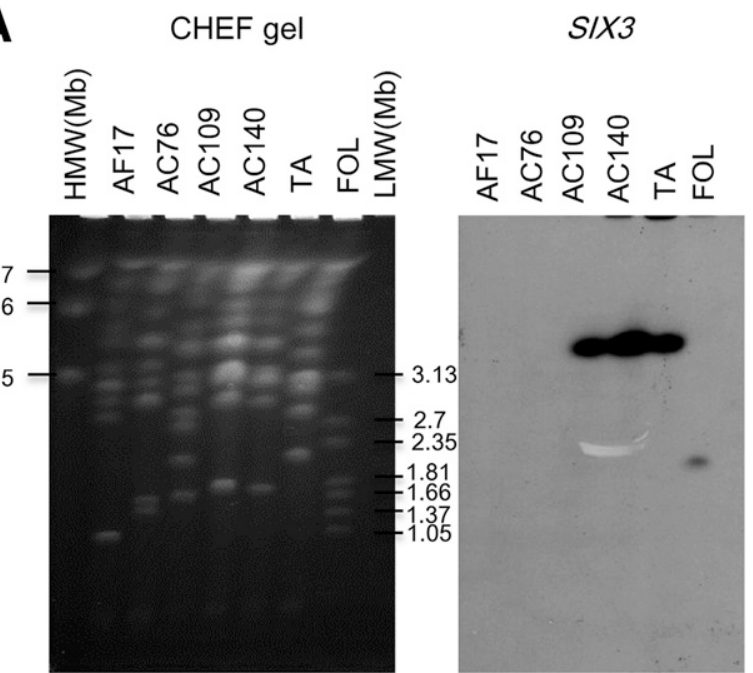

B

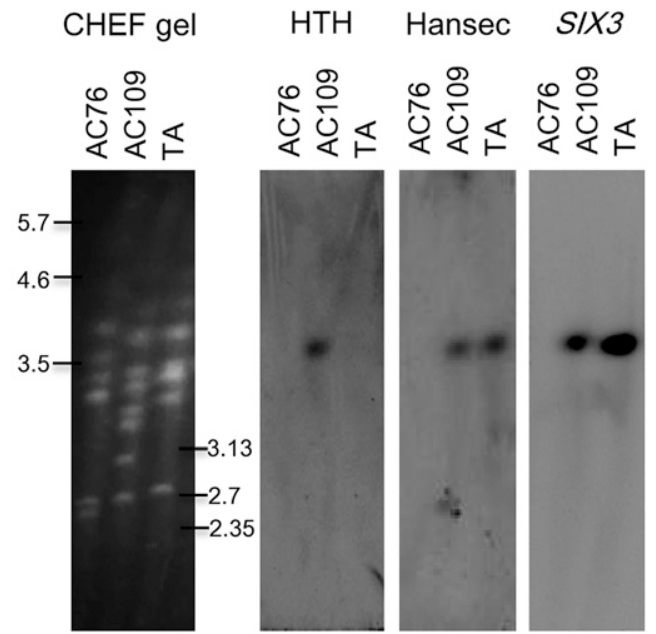

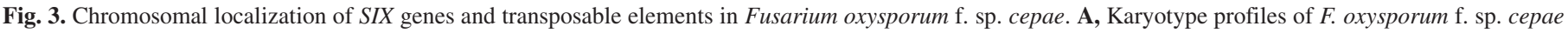

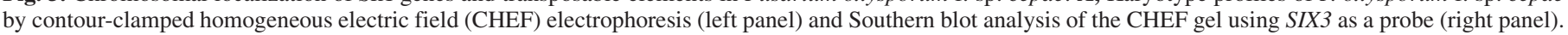

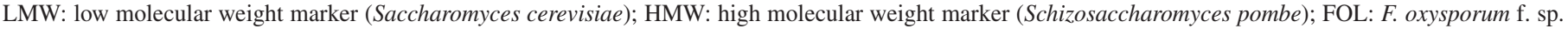
lycopersici (race 2). B, Southern blot analysis of the CHEF gel probed with 244-bp fragment (HTH), 392-bp fragment (Hansec), and SIX3 homolog (SIX3). 
AC214, AC217, and AC222) showed no or very low virulence in onion seedlings. It is reasonable to speculate, therefore, that these isolates may not be $F$. oxysporum f. sp. cepae but rather a nonpathogenic $F$. oxysporum that infects onions. Indeed, such nonpathogenic $F$. oxysporum have been isolated from symptomatic sugar beets (41). The high degree of genetic variation among Welsh onion isolates compared with onion isolates might be related to the long cultivation history of Welsh onions, which have been planted in Japan since the 8th century or earlier, while the cultivation of common onions in Japan started in 1871 using seeds imported from the United States.

In the vegetative compatibility test, heterokaryon formation was limited, even though the isolates belonged to the same clade; five types of VCGs and 18 SMVs were observed. Such VCG diversity and a high number of SMVs have also been reported in F. oxysporum isolated from onion in Turkey, in which $48 \mathrm{SMVs}$ were detected in 75 isolates (3), and in those isolated from a common bean field in Spain in which 96 VCGs were detected in 128 isolates (2). However, the isolates belonging to the IGS-clade $\mathrm{H}$ formed heterokaryons only with other isolates in the same clade, suggesting that isolates contained in the clade are genetically closely related.

In the present study, we tested for VCG types of $F$. oxysporum isolated from onion and Welsh onion by using IR-SCAR marker primers that can amplify specific PCR products (392 and $244 \mathrm{bp}$ ) from VCG0421 and VCG0425. The IR-SCAR marker primers, which target DNA between the long terminal repeat insertion sites of retrotransposons, were designed based on specific DNA fragments that displayed inter-retrotransposon amplified polymorphism. The IR-SCAR marker primers helped identify VCG0421 and VCG0425 of $F$. oxysporum f. sp. cepae isolated from South Africa and Colorado (32). Both PCR products (392 and $244 \mathrm{bp}$ ) were detected only in the F. oxysporum f. sp. cepae isolates belonging to the IGS-clade $\mathrm{H}$. However, four isolates (AC140, AC150, AC205, and TA) generated only a 392-bp band. Furthermore, $F$. oxysporum f. sp. cepae isolates belonging to the IGS-clade $\mathrm{H}$ were grouped into the same VCG. Taken together, these results suggest that $F$. oxysporum f. sp. cepae isolates belonging to the IGS-clade $\mathrm{H}$ are not a monoclonal group, although they are genetically very similar.

Transposable elements, including retrotransposons, can travel throughout the genome and can cause genetic changes due to insertion or excision (15). This mechanism may have provided genetic variation and evolution of new phenotypes of fungi (30). For example, Inami et al. (13) reported a new mechanism underlying the emergence of $F$. oxysporum $\mathrm{f}$. sp. lycopersici race 3 in which the AVR1 gene (SIX4) was disrupted by the transposon Hormin. In this context, it is interesting that the four isolates (AC140, AC150, AC205, and TA) that did not generate the 244-bp fragment exhibited high virulence in the onion cultivars used as hosts. Target sequences of the IR-SCAR marker primers are included in the retrotransposon sequences as described above, suggesting that the genomic region containing retrotransposon sequences may be absent among these four isolates. Thus, genome regions flanking the 244-bp DNA might be involved in virulence, such as virulence via the production of an effector protein. In addition, Southern blot analysis revealed that target sequences of IR-SCAR markers as well as SIX3 homologs were located on the same $4 \mathrm{Mb}$-sized chromosome. In F. oxysporum f. sp. lycopersici, most of the SIX genes are known to be located on chromosome 14 (the pathogenicity chromosome), which is enriched in the transposable elements (24). Thus, it is plausible that the $4 \mathrm{Mb}$-sized chromosome of $F$. oxysporum $\mathrm{f}$. sp. cepae could be a pathogenicity chromosome, similar to chromosome 14 of $F$. oxysporum f. sp. lycopersici, despite their size difference (chromosome 14 of F. oxysporum $\mathrm{f}$. sp. lycopersici is $2 \mathrm{Mb}$ ).

We observed that $F$. oxysporum f. sp. cepae isolates belonging to IGS-clade H contain SIX3, SIX5, and SIX7 homologs, and that Welsh onion isolates and nonpathogenic onion isolates of
F. oxysporum f. sp. cepae do not contain any $S I X$ genes. To our knowledge, this is the first report stating that SIX3 and SIX5 homologs are present in a forma specialis other than f. $s p$. lycopersici. These results strongly suggest that $F$. oxysporum f. sp. cepae isolates belonging to IGS-clade $\mathrm{H}$ are genetically different from $F$. oxysporum isolated from Welsh onions. Further investigation is required to determine whether the SIX homologs of $F$. oxysporum f. sp. cepae are involved in inducing virulence in onion.

In the inoculation test, most of the fungal isolates, other than those belonging to the IGS-clade $\mathrm{H}$, displayed low or no virulence in onion seedlings (Table 2). Although the virulence of these isolates in Welsh onion is unclear at present, these isolates may have adapted to Welsh onion as their host since there is a long history of cultivation of Welsh onion in Japan. However, some isolates from Welsh onion (AF88, AF91, and AF95) were highly virulent in onion seedlings. These isolates may provide new insights into the mechanisms of development of virulence in onion among indigenous $F$. oxysporum f. sp. cepae populations in Japan.

\section{ACKNOWLEDGMENTS}

This work was supported in part by the Global COE Program "Advanced Utilization of Fungus/Mushroom Resources for Sustainable Society in Harmony with Nature" from the Ministry of Education, Culture, Sports, Science, and Technology (MEXT) of Japan, and a Grant-in-Aid for Scientific Research (C) (23580063) from the Japanese Society for Promotion of Sciences (JSPS). We thank A. Sue, T. Yoshida (Takii Seed), and M. Funahashi (Nissan Seed) for providing the diseased plants.

\section{LITERATURE CITED}

1. Akamatsu, H., Taga, M., Kodama, M., Johnson, R., Otani, H., and Kohmoto, K. 1999. Molecular karyotypes for Alternaria plant pathogens known to produce host-specific toxins. Curr. Genet. 35:647-656.

2. Alves-Santos, F. M., Benito, E. P., Eslava, A. P., and Díaz-Mínguez, J. 1999. Genetic diversity of Fusarium oxysporum strains from common bean fields in Spain. Appl. Environ. Microbiol. 65:3335-3340.

3. Bayraktar, H., Türkkan, M., and Dolar, F. S. 2010. Characterization of Fusarium oxysporum f. sp. cepae from onion in Turkey based on vegetative compatibility and rDNA RFLP analysis. J. Phytopathol. 158: 691-697.

4. Chakrabarti, A., Rep, M., Wang, B., Ashton, A., Dodds, P., and Ellis, J. 2011. Variation in potential effector genes distinguishing Australian and non-Australian isolates of the cotton wilt pathogen Fusarium oxysporum $\mathrm{f}$. sp. vasinfectum. Plant Pathol. 60:232-243.

5. Correll, J. C., Klittich, C. J. R., and Leslie, J. F. 1987. Nitrate nonutilizing mutants of Fusarium oxysporum and their use in vegetative compatibility tests. Phytopathology 77:1640-1646.

6. Dissanayake, M. L. M. C., Kashima, R., Tanaka, S., and Ito, S. 2009. Genetic diversity and pathogenicity of Fusarium oxysporum isolated from wilted Welsh onion in Japan. J. Gen. Plant Pathol. 75:125-130.

7. Dissanayake, M. L. M. C., Kashima, R., Tanaka, S., and Ito, S. 2009. Pathogenic variation and molecular characterization of Fusarium species isolated from wilted Welsh onion in Japan. J. Gen. Plant Pathol. 75:37-45.

8. Edel, V., Steinberg, C., Avelange, I., Laguerre, G., and Alabouvette, C. 1995. Comparison of three molecular methods for the characterization of Fusarium oxysporum strains. Phytopathology 85:579-585.

9. FAOSTAT. 2012. Food and agricultural organization of the United Nations. http://faostat.fao.org/site/291/default.aspx

10. Fourie, G., Steenkamp, E. T., Gordon, T. R., and Viljoen, A. 2009. Evolutionary relationships among the Fusarium oxysporum f. sp. cubense vegetative compatibility groups. Appl. Environ. Microbiol. 75:4770-4781.

11. Fraser-Smith, S., Czislowski, E., Meldrum, R. A., Zander, M., O’Neill, W., Balali, G. R., and Aitken, E. A. B. 2014. Sequence variation in the putative effector gene SIX8 facilitates molecular differentiation of Fusarium oxysporum f. sp. cubense. Plant Pathol. 63:1044-1052.

12. Houterman, P. M., Speijer, D., Dekker, H. L., de Koster, C. G., Cornelissen, B. J. C., and Rep, M. 2007. The mixed xylem sap proteome of Fusarium oxysporum-infected tomato plants. Mol. Plant Pathol. 8: 215-221.

13. Inami, K., Yoshioka-Akiyama, C., Morita, Y., Yamasaki, M., Teraoka, T., and Arie, T. 2012. A genetic mechanism for emergence of races in Fusarium oxysporum f. sp. lycopersici: Inactivation of avirulence gene AVR1 by transposon insertion. PLoS ONE 7:e44101. 
14. Inden, H., and Asahira, T. 1990. Japanese bunching onion (Allium fistulosum L.). Pages 159-178 in: Onions and Allied Crops. H. D. Rabinowitch and J. L. Brewster, eds. CRC Press, Boca Raton, FL.

15. Kang, S., Lebrun, M. H., Farrall, L., and Valent, B. 2001. Gain of virulence caused by insertion of a Pot3 transposon in a Magnaporthe grisea avirulence gene. Mol. Plant-Microbe Interact. 14:671-674.

16. Kashiwa, T., Inami, K., Fujinaga, M., Ogiso, H., Yoshida, T., Teraoka, T., and Arie, T. 2013. An avirulence gene homolog in the tomato wilt fungus Fusarium oxysporum f. sp. lycopersici race 1 functions as a virulence gene in the cabbage yellows fungus $F$. oxysporum $\mathrm{f}$. sp. conglutinans. J. Gen. Plant Pathol. 79:412-421.

17. Kimura, M. 1980. A simple method for estimating evolutionary rates of base substitutions through comparative studies of nucleotide sequences. J. Mol. Evol. 16:111-120.

18. Kodama, F. 1977. Fusarium wilt disease of Welsh onion caused by Fusarium oxysporum. Ann. Phytopathol. Soc. Jpn. 43:340. (Abstract in Japanese)

19. Kodama, F. 1983. Studies on basal rot of onion caused by Fusarium oxysporum f. sp. cepae and its control. Rep. Hokkaido Pref. Agric. Exp. Stn. 39:1-65

20. Komada, H. 1975. Development of a selective medium for quantitative isolation of Fusarium oxysporum from natural soil. Rev. Plant Prot. Res. 8:114-124.

21. Leslie, J. F. 1993. Vegetative compatibility in fungi. Annu. Rev. Phytopathol. 31:127-151.

22. Leslie, J. F., and Summerell, B. A. 2006. The Fusarium Laboratory Manual. Blackwell Publishing, Ames, IA.

23. Lievens, B., Houterman, P. M., and Rep, M. 2009. Effector gene screening allows unambiguous identification of Fusarium oxysporum f. sp. lycopersici races and discrimination from other formae speciales. FEMS Microbiol. Lett. 300:201-215.

24. Ma, L.-J., van der Does, H. C., Borkovich, K. A., Coleman, J. J., Daboussi, M.-J., Di Pietro, A., Dufresne, M., Freitag, M., Grabherr, M., Henrissat, B., Houterman, P. M., Kang, S., Shim, W.-B., Woloshuk, C., Xie, X., Xu, J.-R., Antoniw, J., Baker, S. E., Bluhm, B. H., Breakspear, A., Brown, D. W., Butchko, R. A. E., Chapman, S., Coulson, R., Coutinho, P. M., Danchin, E. G. J., Diener, A., Gale, L. R., Gardiner, D. M., Goff, S., Hammond-Kosack, K. E., Hilburn, K., Hua-Van, A., Jonkers, W., Kazan, K., Kodira, C. D., Koehrsen, M., Kumar, L., Lee, Y.-H., Li, L., Manners, J. M., Miranda-Saavedra, D., Mukherjee, M., Park, G., Park, J., Park, S.-Y., Proctor, R. H., Regev, A., Ruiz-Roldan, M. C., Sain, D., Sakthikumar, S., Sykes, S., Schwartz, D. C., Turgeon, B. G., Wapinski, I., Yoder, O., Young, S., Zeng, Q., Zhou, S., Galagan, J., Cuomol, C. A., Kistler, H. C., and Rep, M. 2010. Comparative genomics reveals mobile pathogenicity chromosomes in Fusarium. Nature 464:367-373.

25. O’Donnell, K., Gueidan, C., Sink, S., Johnston, P. R., Crous, P. W., Glenn, A., Riley, R., Zitomer, N. C., Colyer, P., Waalwijk, C., van der Lee, T., Moretti, A., Kang, S., Kim, H.-S., Geiser, D. M., Juba, J. H., Baayen, R. P., Cromey, M. G., Bithell, S., Sutton, D. A., Skovgaard, K., Ploetz, R., Kistler, H. C., Elliott, M., Davis, M., and Sarver, B. A. J. 2009. A two-locus DNA sequence database for typing plant and human pathogens within the Fusarium oxysporum species complex. Fungal Genet. Biol. 46:936-948.

26. O’Donnell, K., Kistler, H. C., Cigelnik, E., and Ploetz, R. C. 1998. Multiple evolutionary origins of the fungus causing Panama disease of banana: Concordant evidence from nuclear and mitochondrial gene genealogies. Proc. Natl. Acad. Sci. USA 95:2044-2049.

27. Rep, M., and Kistler, H. C. 2010. The genomic organization of plant pathogenicity in Fusarium species. Curr. Opin. Plant Biol. 13:420-426.
28. Rep, M., Van Der Does, H. C., Meijer, M., Van Wijk, R., Houterman, P. M., Dekker, H. L., and Cornelissen, B. J. 2004. A small, cysteine-rich protein secreted by Fusarium oxysporum during colonization of xylem vessels is required for I-3-mediated resistance in tomato. Mol. Microbiol. 53:1373-1383.

29. Saitou, N., and Nei, M. 1987. The neighbor-joining method: A new method for reconstructing phylogenetic trees. Mol. Biol. Evol. 4:406-425.

30. Schmidt, S. M., Houterman, P. M., Schreiver, I., Ma, L., Amyotte, S., Chellappan, B., Boeren, S., Takken, F. L., and Rep, M. 2013. MITEs in the promoters of effector genes allow prediction of novel virulence genes in Fusarium oxysporum. BMC Genomics 14:119.

31. Schwartz, H. F., and Mohan, S. K. 2008. Compendium of Onion and Garlic Diseases and Pests, 2nd ed. American Phytopathological Society, St. Paul, MN.

32. Southwood, M. J., Viljoen, A., Mostert, G., and McLeod, A. 2012. Molecular identification of two vegetative compatibility groups of Fusarium oxysporum f. sp. cepae. Phytopathology 102:204-213.

33. Southwood, M. J., Viljoen, A., Mostert, L., Rose, L. J., and McLeod, A. 2012. Phylogenetic and biological characterization of Fusarium oxysporum isolates associated with onion in South Africa. Plant Dis. 96: 1250-1261.

34. Swift, C. E., Wickliffe, E. R., and Schwartz, H. F. 2002. Vegetative compatibility groups of Fusarium oxysporum f. sp. cepae from onion in Colorado. Plant Dis. 86:606-610.

35. Takakuwa, M., Saito, I., Ishizaki, N., and Kodama, F. 1977. Host range of Fusarium oxysporum f. sp. cepae, causal fungus of Fusarium basal rot of onion. Ann. Phytopathol. Soc. Jpn. 43:479-481.

36. Tamura, K., Dudley, J., Nei, M., and Kumar, S. 2007. MEGA4: Molecular evolutionary genetics analysis (MEGA) software version 4.0. Mol. Biol. Evol. 24:1596-1599.

37. Thatcher, L. F., Gardiner, D. M., Kazan, K., and Manners, J. M. 2012. A highly conserved effector in Fusarium oxysporum is required for full virulence on Arabidopsis. Mol. Plant-Microbe Interact. 25:180-190.

38. Thompson, J. D., Higgins, D. G., and Gibson, T. J. 1994. CLUSTAL W: Improving the sensitivity of progressive multiple sequence alignment through sequence weighting, position-specific gap penalties and weight matrix choice. Nucleic Acids Res. 22:4673-4680.

39. Van Der Does, H. C., Lievens, B., Claes, L., Houterman, P. M., Cornelissen, B. J., and Rep, M. 2008. The presence of a virulence locus discriminates Fusarium oxysporum isolates causing tomato wilt from other isolates. Environ. Microbiol. 10:1475-1485.

40. Van der Does, H. C., and Rep, M. 2007. Virulence genes and the evolution of host specificity in plant-pathogenic fungi. Mol. Plant-Microbe Interact. 20:1175-1182.

41. Webb, K. M., Case, A. J., Brick, M. A., Otto, K., and Schwartz, H. F. 2013. Cross pathogenicity and vegetative compatibility of Fusarium oxysporum isolated from sugar beet. Plant Dis. 97:1200-1206.

42. White, T. J., Bruns, T., Lee, S. J. W. T., and Taylor, J. W. 1990. Amplification and direct sequencing of fungal ribosomal RNA genes for phylogenetics. Pages 315-322 in: PCR Protocols: A Guide to Methods and Applications. M. A. Innis, D. H. Gelfand, J. J. Sninsky, and T. J. White, eds. Academic Press, New York.

43. Widodo, K. N., Kobayashi, K., and Ogoshi, A. 2008. Vegetative compatibility groups within Fusarium oxysporum f. sp. cepae in HokkaidoJapan. Microbiol. Indonesia 2:39-43.

44. Yakuwa, T. 2006. Welsh onion or Japanese bunching onion. Pages 165-166 in: The Japanese Society for Horticultural Science Horticulture in Japan. Shokabo Publications, Tokyo, Japan. 